\title{
A DIMENSÃO HUMANA NO PROCESSO DE PROJETO: ANÁLISE DE TIPOLOGIAS HABITACIONAIS EM BELÉM-PARÁ
}

\author{
LA DIMENSIÓN HUMANA EN EL PROCESO DE PROYECTO: ANÁLISIS EN TIPOLOGÍAS DE \\ VIVIENDA EN BELÉM-PARÁ
}

THE HUMAN DIMENSION IN THE DESIGN PROCESS: ANALYSIS IN HOUSING TYPOLOGIES IN BELÉMPARÁ

\section{PAIXÃO, ROSINEIDE TRINDADE DA}

Mestrado, Programa de Pós-graduação em Arquitetura e Urbanismo da Universidade Federal do Pará. E-mail: rosineidetrindade@gmail.com

\section{PERDIGÃO, ANA KLAUDIA DE ALMEIDA VIANA}

Professora Associada IV da Faculdade de Arquitetura e Urbanismo e do Programa de Pós-graduação em Arquitetura e Urbanismo da Universidade Federal do Pará. Coordenadora do Laboratório Espaço e Desenvolvimento Humano - LEDH-UFPA. E-mail: klaudiaufpa@gmail.com

\section{RESUMO}

Apresentam-se os resultados de uma pesquisa de mestrado em que se procurou responder como o arquiteto pode incluir a dimensão humana no processo projetual de habitação de interesse social para a Amazônia. Trata-se de um estudo longitudinal realizado com famílias atendidas por programa de intervenção pública em um assentamento precário na cidade de Belém (PA), cujas áreas de interferência são a comunidade Cubatão e seu correspondente projeto de reassentamento, o projeto Taboquinha, ambos localizados no distrito de Icoaraci. Partiu-se da premissa de que a dimensão humana pode ser explorada para instrumentalização do projeto arquitetônico adotando como referência estudos urbanos com percursos teóricos que possam auxiliar a concepção arquitetônica, por meio de categorias analíticas de base topológica, as quais permitem a investigação da vida espacial no contexto da habitação. A pesquisa demonstrou que a ampliação do olhar sobre a dimensão humana ultrapassa os aspectos ligados ao espaço geométrico e adentra as relações espaciais que o usuário mantém com o ambiente construído em uso, situação que ficou evidente pela seleção de categorias analíticas de natureza topológica para descrição de relações espaciais significativas para os moradores. Os resultados demonstraram que na casa de origem dos moradores foram identificadas as qualidades espaciais proporcionadas pelo uso adequado dessas categorias, ainda que em meio à informalidade, enquanto que, na casa destino, tais qualidades estão ausentes. Destaca-se que as categorias, uma vez evidenciadas nas casas de origem dos moradores (palafita), podem somar para a contínua caracterização da palafita amazônica.

PALAVRAS-CHAVE: projeto de arquitetura; habitação social; dimensão humana; categorias analíticas; Amazônia.

\section{RESUMEN}

Se presentan los resultados de una investigación de maestría, en la que se intentó responder cómo el arquitecto puede incluir la dimensión humana en el proceso de diseño de viviendas de interés social para la Amazonía. Se trata de un estudio longitudinal realizado con familias asistidas por un programa de intervención pública en un asentamiento precario de la ciudad de Belém (PA), cuyas áreas de injerencia son la comunidad de Cubatão y su correspondiente proyecto de reasentamiento, el proyecto Taboquinha, ambos ubicados en el distrito de Icoaraci. Partimos de la premisa de que la dimensión humana puede ser explorada para la instrumentalización del proyecto arquitectónico, adoptando como referencia estudios urbanos con caminos teóricos que puedan ayudar al diseño arquitectónico, a través de categorías analíticas de base topológica que permitan la investigación de la vida espacial en el contexto de la vivienda. La investigación mostró que la ampliación de la mirada sobre la dimensión humana va más allá de los aspectos relacionados con el espacio geométrico y entra en las relaciones espaciales que el usuario mantiene con el entorno construido en uso, situación que se evidenció por la selección de categorías analíticas topológicas para la descripción de las relaciones espaciales significativas para los residentes. Los resultados mostraron que en el hogar de origen de los residentes se identificaron las cualidades espaciales que brinda el uso adecuado de estas categorías, incluso en medio de la informalidad, mientras que en el hogar de destino tales cualidades están ausentes. Es de destacar que las categorías, una vez evidenciadas en las casas de origen de los pobladores (zanco), pueden sumarse a la caracterización continua del zanco amazónico.

PALABRAS CLAVES: diseño arquitectonico; habitación social; dimensión humana; categorías analíticas; Amazónia.

\section{ABSTRACT}

This article presents the results of a master's research, in which an attempt was made to answer how the architect can include the human dimension in the design process of housing of social interest for the Amazon. This is a longitudinal study carried out with families assisted by a public intervention program in a precarious settlement in the city of Belém (PA), whose areas of interference are the Cubatão community and its corresponding resettlement project, the Taboquinha project, both located in the district of Icoaraci. It started from the premise that the human dimension can be explored for the instrumentalization of the architectural project, adopting as a reference urban studies with theoretical paths that can help the architectural design through topologically-based analytical categories, which allow the investigation of spatial life in the context of housing. The research showed that the broadening of the view on human dimension goes beyond aspects related to geometric space and enters the spatial relationships that the user maintains with the built environment in use, a situation that was evident by the selection of topological analytical categories for the description of significant spatial relationships for residents. The results showed that the spatial qualities provided by the proper use of these categories were identified in the residents' home of origin, even in the midst of informality, while in the home destination such qualities were absent. It is noteworthy that the categories, once evidenced in the residents' houses of origin (stilt houses), can add to the continuous characterization of the Amazonian stilt housing.

KEYWORDS: architecture design; social housing; human dimension; analytical categories; the Amazon.

Recebido em: 21/02/2020 Aceito em: 18/08/2021 


\section{INTRODUÇÃO}

A produção de habitação social na Amazônia segue um modelo amplamente padronizado e difundido em diferentes regiões brasileiras, sem atenção ao contexto cultural e aos modos de habitar da população local, situação que demonstra um interesse em suprir uma demanda quantitativa no setor e revela uma desvalorização da dimensão humana no projeto arquitetônico, acarretando a baixa qualidade dos espaços construídos nesta produção. De fato, em muitas situações observa-se que as necessidades e expectativas humanas deixam de ser valorizadas ou sequer são consideradas no processo de projeto de habitação social, pois as demandas concentram-se na produção em larga escala, objetivando produzir grande quantidade de moradia. Contudo, nesta produção no espaço urbano evidencia-se algo já discutido por Gehl (2013), pois a negligência da dimensão humana na arquitetura gera espaços monótonos e de difícil adaptação, os quais não permitem a interação "saudável" entre usuário e espaço construído.

Nesse sentido, o presente artigo resulta de uma pesquisa de mestrado realizada no Programa de PósGraduação em Arquitetura e Urbanismo e vinculada ao Laboratório Espaço e Desenvolvimento Humano (LEDH/PPGA/UFPA). A investigação (PAIXÃO, 2019) buscou responder de que modo o arquiteto pode incluir, no processo projetual de habitação de interesse social para a Amazônia, a dimensão humana. Para tanto, buscou-se apoio em estudos referentes ao espaço urbano acerca da valorização da dimensão humana, especificamente nos estudos de Gehl (2013), em virtude de seu interesse pelo resgate da abordagem humana no ambiente construído urbano, utilizando para isso categorias que, via de regra, revelam qualidades espaciais a serem perseguidas no processo de projeto e encontram correspondência nos parâmetros projetuais de Alexander (1977). Pretendeu-se, portanto, extrair de tais estudos uma articulação entre categorias analíticas de natureza topológica e as características geométricas na escala do edifício como um caminho para compreender a transição entre a casa de origem produzida espontaneamente e a casa de destino entregue pela equipe técnica do órgão executor da política habitacional local. Desse modo, as relações espaciais estabelecidas entre usuário e espaço construído mostram-se oportunas quando também são discutidas na escala do edifício, pois permitem a inserção da dimensão humana no projeto de arquitetura, podendo, desta forma, auxiliar com uma lógica de projeto humanizada na concepção arquitetônica.

As investigações foram feitas por meio de um estudo longitudinal realizado no contexto de um programa de intervenção pública em assentamento precário na cidade de Belém (PA), cujas áreas de interferência são conhecidas como comunidade Cubatão e seu correspondente projeto de reassentamento denominado Projeto Taboquinha, ambos localizados no distrito de Icoaraci, Belém, Pará. Foi feito o acompanhamento das famílias nesse processo de remanejamento e reassentamento, utilizando técnicas de pesquisa com abordagem multimétodo que permitiram selecionar e investigar as categorias analíticas com o objetivo de registrar percepções e relações espaciais, hábitos culturais estabelecidos na casa de origem (casa da comunidade Cubatão) e sua continuação ou ruptura na casa de destino (casa do projeto Taboquinha). $O$ estudo das categorias de análise objetivou contribuir com a instrumentalização do projeto ao inseri-las como ponto de partida no processo projetual, como uma escolha que acena para uma atuação profissional de arquitetos mais engajada e comprometida com a qualidade da produção de habitação social na Amazônia.

Portanto, este texto apresenta a sistematização das categorias analíticas desenvolvidas na dissertação (PAIXÃO, 2019), bem como as decisões projetuais apontadas a partir das mesmas, as quais contribuem no resgate da dimensão humana no projeto de arquitetura, uma vez que permitiram a compreensão teórica de soluções significativas para o usuário, contribuindo, dessa formam para a melhor adaptação habitacional dos moradores reassentados por programas de intervenção pública na Amazônia.

\section{A DIMENSÃO HUMANA NO PROJETO DE ARQUITETURA}

Os estudos de Gehl (2013) referentes à dimensão humana no espaço urbano têm se destacado pela construção de cidades que valorizam as pessoas e suas mais diversas necessidades, incluindo as percepções espaciais oportunizadas pelos sentidos humanos, que se expressam pela interação entre usuário e espaço construído. Para esse autor, a vitalidade das cidades está intrinsicamente ligada à da dimensão humana. Na mesma direção, Barros, Pina e Samg (2011) defendem que, na arquitetura, ambientes enriquecedores, vivos e saudáveis são a resposta da canalização das necessidades humanas.

Ao conceituar a dimensão humana na área, Muñoz (2013) diz que se trata do modo consciente com que ela considera a interação com os futuros usuários, objetivando elaborar propostas que conduzam para a introdução da sua melhoria de vida. O autor relata que essa interação evidencia uma troca entre a arquitetura e os usuários, e que o arquiteto deve perceber e refletir sobre isso, pensando, primeiramente, nos condicionantes concretos oriundos da interação entre ser humano e espaço construído para, 
posteriormente, elaborar propostas capazes de melhorá-los. Esse conceito revela, portanto, a importância dos estudos relacionados à interação entre ser humano e espaço construído, o que, segundo Perdigão (2012), é uma área de grande relevância para a atuação profissional do arquiteto e urbanista, a qual abre caminho para a investigação do projeto de arquitetura abrangendo os valores daquele que concebe e daquele que usa o espaço arquitetônico. Essa investigação passa pela compreensão de qualidades espaciais que ultrapassam o espaço geométrico e só podem ser apreendidos por meio da vivência espacial, uma vez que o âmago da questão arquitetônica, segundo Elali e Pinheiro (2003), está não apenas na existência do ser humano, mas, principalmente, nas relações bidirecionais entre pessoa e ambiente, ou seja, no entendimento de que tanto a pessoa influencia o meio onde está inserida quanto ela é influenciada por ele.

Tal situação já era defendida por Broadbent (1973) ao dizer que o usuário estabelece uma relação perceptiva com o edifício, a qual se evidencia por um processo que ocorre entre os estímulos recebidos pelos sentidos humanos e as experiências passadas, vivenciadas pelos usuários, os quais, atuando juntos, determinam as novas reações humanas diante de um edifício. Elali e Pinheiro (2013) apontam, ainda, que quanto mais uma pessoa vivencia um lugar, mais elementos subjetivos ela tende a associar ao mesmo, os quais serão decisivos na sua atuação como usuário. Além disso, quanto mais tempo uma pessoa vive em um local, mais se familiariza com ele e o modifica a fim de torná-lo confortável para si, de modo que as percepções espaciais passam a ocorrer de dentro para fora, sendo influenciadas por suas referências.

Tais referências são defendidas por Malard (2006) como sendo parte do passado de um sujeito, ou seja, a sua tradição cultural. Elas governam a percepção do indivíduo sobre o espaço presente, correspondendo a um passado que trata das experiências cotidianas vivenciadas espacialmente, ou seja, o espaço vivido que, segundo a autora, está impregnado de emoções boas ou ruins, e, portanto, o resultado da interação do ser com o espaço.

Também baseando-se em experiências na área da psicologia ambiental, Broadbent (1973) indica alguns dos efeitos prejudiciais da interação entre ser humano e espaço construído. O autor critica a padronização, por exemplo, ao afirmar que a consciência, a percepção e o fluxo "normal" do pensamento só podem se manter em ambientes que mudem constantemente, pois, quando não há mudança, se estabelece um estado de privação sensorial que acarreta aborrecimento, desassossego, falta de concentração, inclusive redução da inteligência humana. Além disso, o pesquisador ressalta que a necessidade de variação instintivamente exigido pelo ser humano e que está relacionada a razões estéticas, a partir de bases fisiológicas e psicológicas. Sob esta perspectiva, uma mudança no ambiente construído estimula mecanismos internos que são responsáveis pela percepção e pela resposta rápida às diversas situações vivenciadas, aumentando, consequentemente, o rendimento humano.

Nesse sentido, as pesquisas do Laboratório Espaço e Desenvolvimento Humano da Universidade Federal do Pará (LEDH/UFPA) têm se concentrado na busca por situar o ser humano que usa o espaço no centro das operações projetuais, uma vez que se compreende a importância da relação que ele estabelece com o espaço construído, bem como as consequências dessa relação, sejam elas positivas ou negativas. Para suas investigações, o Laboratório utiliza como recorte de pesquisa o espaço habitacional, por causa do reconhecimento da complexidade que envolve os espaços de grande permanência humana, apresentando, desta forma, características primordiais na investigação tanto de procedimentos relacionados à concepção projetual, quanto no atendimento efetivo do programa de necessidades (PERDIGÃO, 2012). Dentro do recorte de pesquisa do laboratório, isto é, o espaço habitacional, encontram-se temáticas relacionadas a investigações projetuais no campo da produção de habitação de interesse social na Amazônia, pois, a partir dos estudos desenvolvidos, ela demonstrou ser uma área na qual se evidenciam muitos conflitos físico/espaciais, os quais reforçaram questões relevantes sobre a interação entre ser humano e espaço construído, como a não valorização da dimensão humana desde a concepção espacial.

Nos estudos do LEDH, são analisados exemplares das habitações tradicionais na Amazônia de modo a identificar tipos e padrões espaciais socialmente construídos que possam subsidiar discussões sobre a produção habitacional urbana, tanto espontânea quanto formal, que incluem as referências do usuário na concepção do projeto de arquitetura (PERDIGÃO, 2012). Nessa direção, destacam-se os trabalhos de Perdigão (2016) e Menezes e Perdigão (2021), os quais, por meio da seleção de categorias analíticas, investigam as relações espaciais nas palafitas na tentativa de descrever e decifrar, por meio dessas relações, qualidades topológicas que, ao se materializarem na habitação ribeirinha da Amazônia, podem auxiliar na produção formal de habitação social em áreas de baixadas na cidade de Belém. As figuras 1 e 2 apresentam a síntese das relações espaciais de natureza topológica identificadas pelas autoras na palafita amazônica. 
Figura 1: Síntese das relações espaciais de natureza topológica na palafita amazônica.

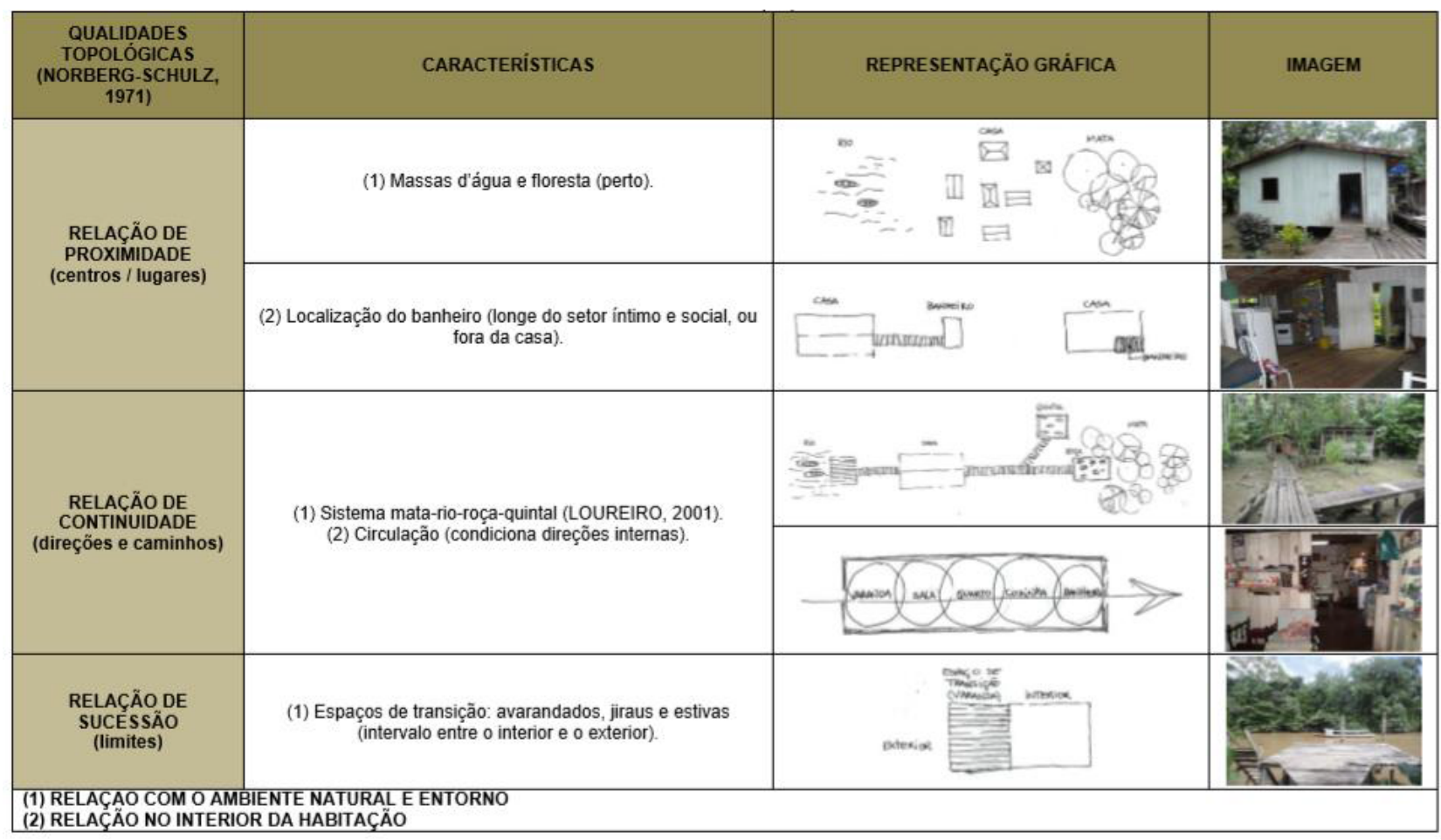

Fonte: Menezes e Perdigão (2021).

Figura 2: Análise topológica de palafita, Afuá (PA).

\begin{tabular}{|l|l|l|l|}
\hline \multicolumn{2}{|c|}{ BAIRRO CAPIM MARINHO } & \\
\hline \\
$\begin{array}{l}\text { RELAÇÃO DE } \\
\text { PROXIMIDADE }\end{array}$
\end{tabular}

Fonte: Perdigão (2016). 


\section{CATEGORIAS ANALÍTICAS COMO PONTO DE PARTIDA NO PROCESSO PROJETUAL}

Com objetivo de fundamentar o campo teórico da concepção projetual, destacam-se as discussões trazidas por Perdigão e Bruna (2009) desde a representação mais tradicional no campo da arquitetura, a geométrica, até as duas representações não tão tradicionais, a topológica e a pulsional, em torno do ponto de partida no processo projetual, sendo as duas últimas de suma importância para a compreensão das relações existentes entre o ser humano e o espaço construído e, consequentemente, da evidência sobre a importância da dimensão humana no espaço construído.

Perdigão e Bruna (2009) consideram que a vivência espacial do ser humano se vincula, por um lado, à regulação existencial em que cabem as representações topológicas e, por outro, às manifestações do inconsciente, cuja representação é pulsional. Por isso, afirmam que a totalidade arquitetônica no processo projetual pode admitir tanto as representações espaciais (que integram espaços da vivência, investigados pelas representações topológica e pulsional) quanto as representações espaciais de aparência (que são as geométricas). As autora afirmam, ainda, que a procura por particularidades na demanda espacial do projeto arquitetônico, tão importante na evidência da dimensão humana no ambiente construído, passa pela investigação da totalidade das representações espaciais do usuário, observando-se o conjunto de representações atribuído ao conjunto de interações entre ser humano e entorno no ciclo vital humano, algo investigado por Piaget (AULT, 1978).

Dessa forma, entende-se que a ampliação do olhar sobre a dimensão humana no ambiente construído necessita ultrapassar aspectos ligados somente ao espaço geométrico e incluir as relações espaciais estabelecidas pelas demais representações que são invisíveis, mas que preenchem de significado os espaços sobre a representação geométrica. Com isso, elas enriquecem as vivências espaciais dos usuários pela qualificação de espaços na concepção arquitetônica e podem ser tomadas como referência para a concepção projetual de espaços, já que oferecem qualidade nas vivências espaciais dos usuários.

Nesse sentido, são as vivências que estabelecem o significado no uso espacial, a partir das quais se associam relações concernentes ao modo pelo qual o morador interage com o espaço construído, oferecendo suporte para a aplicação de categorias analíticas que foram extraídas dos estudos de Gehl (2013) acerca do espaço urbano, mas agora voltadas à escala do edifício, de modo a propor e instrumentalizar a dimensão humana no escopo do projeto de habitação social na Amazônia.

Gehl (2013), ao longo de seus estudos, se utiliza de conceitos, os quais são tomados neste trabalho como categorias analíticas, a saber: distância e espaços de transição suave que, ao serem desenvolvidos, resgatam a figura humana no cenário urbano. O autor demonstra, a partir desses conceitos, como o espaço urbano pode ser pensado e concebido de modo a corresponder às necessidades humanas de maneira positiva, desde que sejam contempladas na concepção projetual. A seguir, apresentam-se essas categorias e um breve posicionamento de alguns autores sobre elas.

\section{Categoria: Distância}

Para evidenciar a dimensão humana no espaço urbano, Gehl (2013) faz um resgate da escala humana incluindo os sentidos humanos, pois eles têm muita importância na percepção espacial, como anteriormente reconhecido por Moholy (1928, apud BARKI, 2009) ao falar da complexidade do espaço, argumentando que, para apreendê-lo, é necessária a participação de todos os sentidos do corpo humano. De modo complementar, Gehl (2013) indica que o desenvolvimento sensorial humano pode ser classificado de acordo com os sentidos de "distância" (envolvendo a visão, a audição e o olfato) e de "proximidade" (que abrange o tato e o paladar). O autor afirma que, no contato entre as pessoas, os sentidos humanos são ativados a distâncias muito diferentes, e esclarece que as distâncias muito longas podem oferecer muitas informações, enquanto as distâncias mais curtas permitem impressões sensoriais muito intensas e emocionalmente significativas. Por isso, no ambiente construído, é muito relevante explorar o uso dessa categoria pelos efeitos que ela possibilita.

Hall (1981) reconheceu quatro zonas de distância/envolvimento entre seres humanos e atividades, bem como as relações emocionais e comunicacionais associadas a elas. Dentre essas zonas, encontra-se a distância pessoal, já que o ser humano tem a tendência de se proteger como uma bolha pessoal e invisível. lachini (2017) consideram essa "bolha" como espaço pessoal (SOMMER, 1969), descrito como uma zona que as pessoas sentem que "é seu espaço", na qual as dimensões não são fixas e podem variar de acordo com o estado interno, a idade, o contexto e a cultura. Sintetizando tal ideia, Gifford (1997) esclarece que o 
espaço pessoal é instável em suas dimensões, varia de acordo com as circunstâncias, só existe quando há interação com outras pessoas e é influenciado por questões individuais e do contato grupal, como a cultura, que é mais perceptível na conformação do espaço.

Como dependendo da cultura em que está inserida cada indivíduo, a conformação do espaço pessoal é diferente (MYERS, 1999 apud GLIBER; CHIPPARI, 2007), Hall (1981) já apontava as possibilidades de conflitos entre pessoas na ocupação dos espaços construídos cujas culturas são diferentes, já que a definição do espaço pessoal difere entre elas. O autor também indicou a importância de se considerar como fator de análise a possibilidade de invasão do espaço pessoal provocada pelo excesso de pessoas em um único lugar. Por sua vez, Heimstra e Mc Farling (1978 apud GLIBER; CHIPPARI, 2007) associaram a satisfação de estar em um ambiente com a preservação do espaço pessoal e, consequentemente, da privacidade, situações que, para os autores, podem evitar casos de estresse.

Considerando a relevância do assunto, Barros et al. (2005) identificaram alguns elementos arquitetônicos que possibilitam a projetação de ambientes confortáveis a partir da consideração do significado de espaço pessoal. Dentre esses elementos, encontra-se a amplidão, o que, segundo os autores, permite a adaptação do ambiente possibilitando ajustes nas distâncias entre as pessoas, pois um ambiente confortável oferece o equilíbrio da tendência humana de afastamento e aproximação. A amplidão diz respeito, obviamente, aos ambientes mais amplos, mas que, de acordo com os autores, também pode ser alcançada por iluminação abundante, pé-direito alto e cores claras nos materiais de acabamento.

Alexander (1977), em seus estudos sobre definições de parâmetros de projeto, materializa a amplidão no espaço por meio do parâmetro Casa Longa e Estreita ${ }^{10}$, o qual, segundo o pesquisador, pode ser explicado pelas leis da matemática. Baseando-se nos estudos de Alexander (1977), Barros (2008) aponta o gradiente de intimidade ${ }^{127}$ como um dos parâmetros que abrangem aspectos importantes da conformação do espaço pessoal. Por sua vez, Reis e Lay (2003) associam as ideias de espaço pessoal e privacidade a partir da interpretação de autores como Kupritz (2000) e Rapoport (1985), para os quais a privacidade está relacionada à possibilidade de controlar, em diferentes graus, a interação entre as pessoas e/ou com outros espaços (quer sejam internos ou externos), sendo possível, deste modo, interromper ou minimizar o fluxo de informações ou estímulos.

Nota-se, com isso, a relevância da categoria distância, cuja análise conduz a aspectos de enorme importância para a conformação do espaço pessoal, o qual pode se materializar espacialmente pela amplidão. Segundo Alexander (1977), a amplidão também pode ser alcançada mediante o parâmetro de projeto Casa Longa e Estreita ${ }^{109}$. Constata-se, ainda, que o espaço pessoal possui estreita relação com o parâmetro projetual gradiente de intimidade ${ }^{127}$, que está fortemente relacionado com o conceito de privacidade defendido por Reis e Lay (2003).

Nesse sentido, aponta-se que a categoria distância no ambiente construído pode oferecer bases para a discussão sobre dimensionamento e configuração espacial, uma vez que, como foi exposto acima, ambientes que não permitem o ajuste da distância, impossibilitando equilíbrio entre afastamento e aproximação, os quais estão intimamente ligados ao espaço pessoal, podem dificultar a apropriação do espaço pelo usuário e comprometer o gradiente de intimidade/privacidade, algo que, como demonstrado, está diretamente ligado à satisfação com a moradia.

\section{Categoria: Espaços de transição suave}

Os espaços de transição suave são descritos por Gehl (2013) como o local onde as edificações e a cidade se encontram. Hertzerberg (1999) os denomina de "intervalo", pois cumprem uma função social, permitindo a transição do espaço público para o privado, dando a experiência do estar "fora" e "dentro" ao mesmo tempo. Esses espaços exercem função relevante tanto no conjunto externo que compõe o espaço urbano quanto no espaço interno, ou seja, em ambientes privados, neste caso, especificamente na habitação.

Para Gehl (2013), os espaços de transição suave limitam o campo visual e definem o espaço individual humano, transmitindo a ideia de organização, conforto e segurança. Eles também funcionam como pontos de troca entre interior e exterior, pois oferecem a chance para a vida dentro das edificações ou em frente a elas, oportunizando também a interação com a vida na cidade (GEHL, 2013).

Para o autor, a inexistência de espaços de transição suave, ou seja, quando há uma transição rígida com fachadas monótonas e fechadas, faz com que a caminhada no espaço urbano se torne mais longa e empobrecida em termos de experiências sensoriais. Assim, Broadbent (1973) dialoga com o pensamento de Gehl (2013) ao refletir sobre os efeitos negativos de espaços monótonos e invariáveis sobre os seres humanos. O autor diz que fachadas marcadas pela monotonia produzem um estado de tédio, 
desassossego, falta de concentração e redução da inteligência humana. Para ele, uma mudança no ambiente estimula os mecanismos internos humanos para a percepção e resposta rápida aos fatos significativos, aumentando, dessa maneira, o desempenho das pessoas.

Os espaços de transição suave também encontram respaldo quanto à sua importância nos estudos de Alexander (1977) sobre definições de parâmetros de projeto, quando define o espaço de transição $0^{112}$, o ambiente de entrada ${ }^{130}$ e as varandas e galerias ${ }^{166}$ como princípios projetuais que proporcionam, dentre tantas qualidades, o equilíbrio entre o público e o privado. Ao interpretar os parâmetros mencionados por Alexander (1977), Barros (2008) ressalta que a transição e a diferenciação entre os espaços demonstram níveis diferentes de intimidade. Para a autora, as relações entre interior e exterior podem trazer qualidade para o espaço e embasar a orientação das pessoas.

Portanto, destaca-se a importância dos espaços de transição suave tanto para o espaço externo (urbano) como para o espaço interno (habitação), pois, como mencionado, eles representam a comunicação do público com o privado por meio de um gradiente que possibilita diversidade, interação, relação, comunicação, vida, apreciação, além de oferecerem proteção à casa, privacidade, possibilidade de estar fora, contudo, protegido pelo ambiente privado.

O quadro 1 apresenta o resumo das categorias e os parâmetros correspondentes identificados em Alexander (1977), além dos quais complementa-se à categoria distância, o conceito de espaço pessoal.

Quadro 1: Resumo das categorias analíticas.

\begin{tabular}{|c|l|l|}
\hline $\begin{array}{c}\text { Categoria } \\
\text { (GEHL, 2013) }\end{array}$ & Conceito complementar à categoria & $\begin{array}{l}\text { Parâmetros de Alexander (1977) associados à } \\
\text { categoria }\end{array}$ \\
\hline Distância & Espaço pessoal (IACHINI, 2017) & $\begin{array}{l}\text { Parâmetro Projetual Casa Longa e Estreita (109) } \\
\text { Parâmetro Projetual Gradiente de Intimidade (127) }\end{array}$ \\
\hline $\begin{array}{c}\text { Espaços de transição } \\
\text { suave }\end{array}$ & & $\begin{array}{l}\text { Parâmetro Projetual Espaço de Transição (112) } \\
\text { Parâmetro Projetual Ambiente de Entrada (130) } \\
\text { Parâmetro Projetual Varandas e Galerias (166) }\end{array}$ \\
\hline
\end{tabular}

Elaboração: Autoras (2021).

\section{COMUNIDADE CUBATÃO E PROJETO TABOQUINHA (ICOARACI, BELÉM, PARÁ, BRASIL)}

Neste item são apresentadas a Comunidade de Cubatão, o Projeto Taboquinha e a metodologia da pesquisa que fundamentou o presente artigo.

\section{Comunidade Cubatão}

A comunidade Cubatão situa-se no Distrito de Icoaraci (DAICO), na porção Norte da cidade de Belém, fazendo parte da área de expansão da capital paraense, pois está localizada a aproximadamente $18 \mathrm{~km}$ do seu centro comercial. A comunidade se originou no entorno de um igarapé chamado Tabocão, por meio de um processo de ocupação informal, semelhante ao que ocorreu no restante da cidade desde sua fundação, no qual as terras de cotas mais baixas foram ocupadas pela população de baixa renda que migrou para a capital em busca de melhoria em suas condições de vida (ABELÉM, 1989). A ocupação ao longo das margens do igarapé é constituída por casas no modelo palafita. A localização da comunidade e da poligonal do projeto Taboquinha, bem como as construções em palafitas presentes no entorno do igarapé, podem ser observadas na Figura 3.

Ao longo dos anos, o adensamento e a ausência de um sistema de saneamento foram os principais fatores que conduziram a comunidade a uma situação de precariedade extrema. Em 2008, isso motivou a realização de uma intervenção na área, conhecida como projeto Taboquinha. Dentre outras questões, a proposta teve como meta melhorar as condições de habitação e de mobilidade naquele assentamento precário, localizado em centro urbano. 
Figura 3: Mapa de localização da comunidade Cubatão e poligonal do projeto Taboquinha.



Fonte: Google Maps (2019) adaptado pelas autoras. Fotos: Pesquisa de campo (2015).

\section{Projeto Taboquinha}

O projeto Taboquinha compreende uma área de intervenção que ultrapassa a área de alcance da comunidade Cubatão. Ele é delimitado por uma poligonal composta pelas ruas Pimenta Bueno, 15 de Agosto e Dois de Dezembro e pela Travessa do Cruzeiro.

O projeto pertence à modalidade "Apoio à Urbanização de Assentamentos Precários" do governo federal, tem contrapartida do governo estadual, sendo o órgão executor a Companhia de Habitação do Pará (COHAB-PA) e o órgão fiscalizador a Caixa Econômica Federal.

As ações previstas envolveram obras integradas de regularização fundiária, serviços de infraestrutura básica, erradicação das palafitas, produção de moradia para atender às famílias remanejadas e trabalho técnico social em parceria com o Movimento Nacional de Luta pela Moradia (COHAB-PA, 2011). De acordo com os dados do levantamento socioeconômico, fornecido pela executora do projeto, ele beneficiaria 1.862 famílias (aproximadamente 9.310 pessoas), sendo de grande impacto por envolver uma alta quantidade de remoção, precisamente, 1.014 imóveis seriam atingidos diretamente com necessidade de remanejamento (COHAB-PA, 2009, 2011).

Com base nos dados apresentados no recebimento do Selo de Mérito ABC/FNSHDU edição 2014, a provisão habitacional foi definida como uma construção de 66 unidades habitacionais térreas, com área de $39 \mathrm{~m}^{2}$, contendo dois quartos, banheiro, sala e cozinha; melhoria de 100 unidades habitacionais de acordo com a necessidade encontrada em cada uma; e construção de 912 unidades habitacionais tipo sobrado com área de 43,62 m² (BRASIL, 2012). 
Figura 4: Blocos habitacionais construídos (2021)

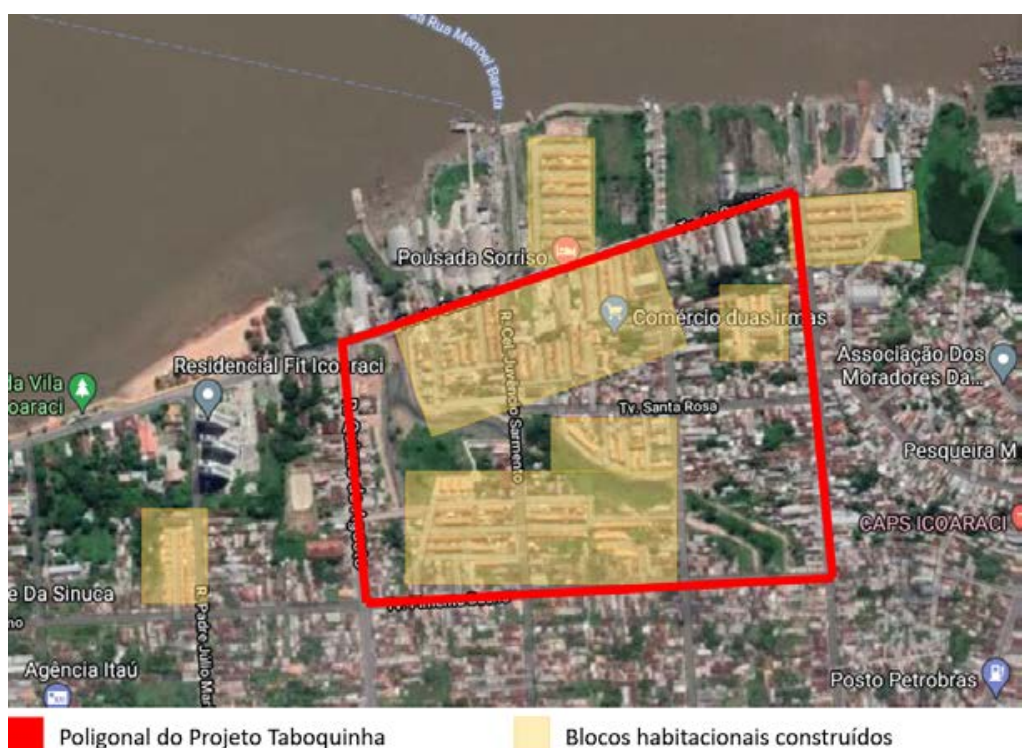

Fonte: Google Maps (2021) adaptado pelas autoras.

As unidades habitacionais, casa (Figura 5a) e sobrado (Figura 5b), apresentam configuração espacial semelhante a de outros projetos de habitação para baixa renda produzidos pelo poder público em diferentes regiões do Brasil, definindo, assim, um modelo de layout rígido, compacto, que demonstra ser apenas reproduzido com vista à produção quantitativa e padronizada, a qual não considera particularidades locais, cultura e modos de habitar, refletindo, portanto, a desvalorização da dimensão humana no projeto arquitetônico da habitação social na Amazônia (BRASIL, 2012).

Figuras 5a e 5b: Casas e sobrados executados pela COHAB-PA no projeto Taboquinha.

$5 a$
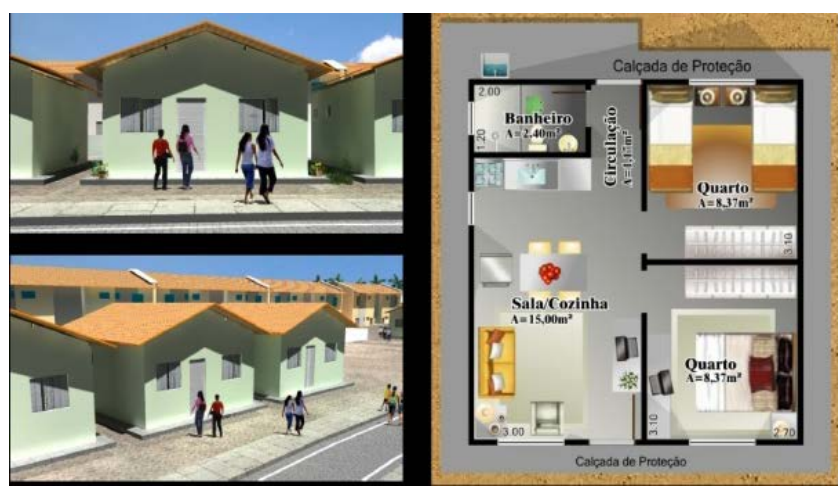

5b 


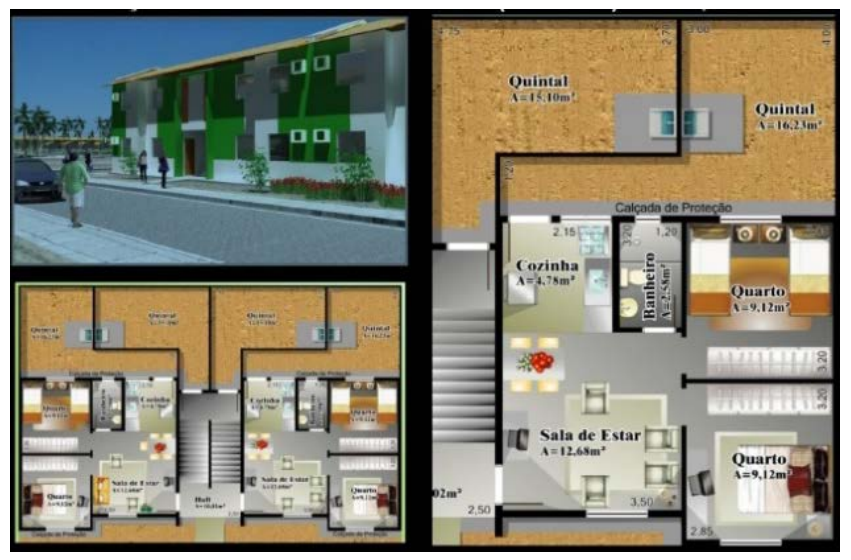

Fonte: Brasil (2012).

\section{Metodologia}

A aplicação das categorias analíticas extraídas dos estudos de Gehl (2013) no espaço urbano foi realizada por meio de um estudo longitudinal entre casa de origem e casa de destino com famílias que habitavam a comunidade Cubatão e posteriormente foram remanejadas pelo projeto Taboquinha.

O estudo foi realizado em duas etapas que somaram informações coletadas antes e após o remanejamento de uma amostra de seis famílias consultadas.

- A primeira etapa de coleta de dados foi realizada no ano de 2015 (antes do remanejamento, ou seja, quando as famílias ainda residiam na comunidade Cubatão) e situa-se no contexto de um projeto de pesquisa denominado "O PAC Urbanização de Assentamentos Precários em Cidades Amazônicas: proposta metodológica para avaliação da produção e ocupação humana na política habitacional em Belém e Macapá", aprovado em 2012 pelo edital CNPq/MICIDADES N.11/2012, o qual contava com o seguinte registro no comitê de ética CAAE: 21653814.4.0000.5172 de 28/10/2014. As técnicas de coleta de dados desta etapa constam de: formulário não verbal que investigou a temporalidade do habitar (PERDIGÃO, 2006), compreendendo registros sobre a casa de origem dos moradores (palafita na comunidade Cubatão) e a casa dos sonhos, bem como o levantamento físico da casa de origem.

- Paralelamente à primeira etapa no contexto do mesmo projeto de pesquisa mencionado, foi realizada a coleta de dados por meio de formulário verbal de adaptação, cuja amostra consultada é diferente da do estudo longitudinal, contudo, foram os resultados desta consulta aos moradores que instigaram a continuação das investigações pelo estudo longitudinal sobre adaptação espacial no projeto Taboquinha.

- Para a segunda etapa, os dados foram coletados no ano de 2019 (após o reassentamento das famílias no projeto Taboquinha), como complemento à pesquisa de mestrado da primeira autora, a qual, para realizar a coleta, foi acompanhada de uma das líderes comunitárias do Cubatão. A coleta compreendeu as seguintes técnicas: levantamento físico e fotográfico das modificações já realizadas pelos moradores na casa destino, ou seja, a casa entregue pelo projeto; uma nova aplicação do formulário não verbal sobre a temporalidade do habitar, bem como a descrição da casa de origem por meio de mapa mental. As técnicas foram aplicadas às mesmas famílias da primeira etapa, contudo, houve uma perda de amostra, já que duas delas já haviam se mudado do projeto Taboquinha.

A metodologia adotada foi de natureza exploratória, na qual foi utilizado o método qualitativo com uma combinação de técnicas de pesquisa que permitiram investigar a dimensão humana na conjuntura da arquitetura em habitação social, a partir de categorias analíticas extraídas de estudos referentes ao espaço urbano, descritas por Gehl (2013) e aplicadas no contexto da produção informal (casas de origem na comunidade Cubatão) e produção formal (casas entregues pelo projeto Taboquinha).

A seguir, são apresentados alguns resultados da consulta a um dos moradores (Morador 2), os quais contemplam a análise das categorias selecionadas para estudo nas casas de origem, casa dos sonhos e casa destino com e sem modificações realizadas pelo morador. O Quadro 2 faz um resumo das técnicas de pesquisa adotadas bem como seus objetivos. 
Quadro 2: Técnicas de pesquisa adotadas para a coleta de dados e seus respectivos objetivos.

\begin{tabular}{|c|c|}
\hline Técnica de Pesquisa & Objetivos \\
\hline Levantamento bibliográfico & $\begin{array}{l}\text { Discutir sobre a valorização da dimensão humana na escala do } \\
\text { edifício. } \\
\text { Selecionar e discutir categorias de análise para evidenciar a } \\
\text { dimensão humana na escala do edifício. }\end{array}$ \\
\hline $\begin{array}{l}\text { Caracterização da área de estudo/Formulário de } \\
\text { adaptação habitacional/Formulário não verbal sobre a } \\
\text { temporalidade do habitar/Levantamento físico e } \\
\text { fotográfico das casa de origem dos } \\
\text { moradores/Levantamento físico e fotográfico das casas } \\
\text { destino dos moradores/Mapa mental }\end{array}$ & $\begin{array}{l}\text { Avaliar a repercussão espacial das categorias analíticas nas } \\
\text { habitações de origem e destino das famílias remanejadas. }\end{array}$ \\
\hline $\begin{array}{l}\text { Levantamento físico e fotográfico para registro das } \\
\text { modificações na casa destino }\end{array}$ & $\begin{array}{l}\text { Associar parâmetros projetuais a partir das categorias analíticas para } \\
\text { o apoio da concepção projetual da habitação de interesse social na } \\
\text { Amazônia. }\end{array}$ \\
\hline
\end{tabular}

Elaboração: Paixão (2019).

\section{RESULTADOS E DISCUSSÃO}

Nas casas de origem dos moradores, foram identificadas as qualidades espaciais proporcionadas pelo uso adequado das categorias ainda que em meio à informalidade, situação que demonstra como as categorias analíticas evidenciam qualidades espaciais a elas relacionadas, e discutidas neste trabalho, como sendo importantes para a valorização da dimensão humana na habitação social.

$\mathrm{Na}$ casa de origem do morador 2 , como pode ser visto na figura 4, encontra-se a categoria distância no formato retangular da casa, bem como no uso de muitas aberturas, situações que proporcionam amplidão ao espaço. A configuração linear com a localização do banheiro e da cozinha disposta ao fundo da unidade (situação comum nas palafitas) permite um gradiente de intimidade que possibilita a privacidade tanto interna (entre os ambientes), quanto externa (vista de fora da casa). Para a categoria espaços de transição suave, encontra-se a varanda frontal, que possibilita segurança, proteção, interação e apreciação do espaço público.

Figura 4: Morador 2 - Casa de origem (Palafita na comunidade Cubatão).

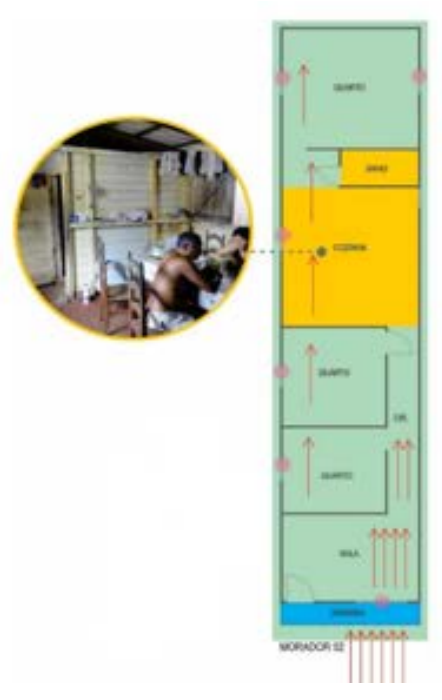

\section{LEGENDA \\ GRADIENTE DE INTIMIDADE: marcado pela configuraçăo \\ espacial que permite a PRIVACIDADE interna e externa.}

COZINHAS AMPLAS E BANHEIROS: localizados no setor mais intimo da casa (PRIVACIDADE e GRADIENTE DE INTIMIDADE).

ESPAÇOS DE TRANSIÇĀO SUAVE: materializado pelas varandas cobertas, em quatro unidades habitacionais e pequeno comércio em uma das unidades.

ABERTURAS: numero considerável de janelas que permitem a amplitude espacial.

FORMATO RETANGULAR: a forma retangular permite maior amplitude espacial.

Elaboração: Paixão (2019).

As casas dos sonhos também refletem as qualidades espaciais trazidas pelas categorias de análise. A casa dos sonhos do morador 2, como pode ser observado na figura 5, "coincidentemente" também demonstra o seu desejo pela presença de elementos espaciais que caracterizam as categorias analíticas. $O$ formato 
retangular, o uso de muitas janelas (aberturas) e o desejo destacado nas falas do morador por ambientes com espaços grandes revelam a necessidade de amplitude espacial, característica que está compreendida pela categoria distância. Novamente, o uso da varanda como espaço de transição suave fortalece a importância deste espaço para este público.

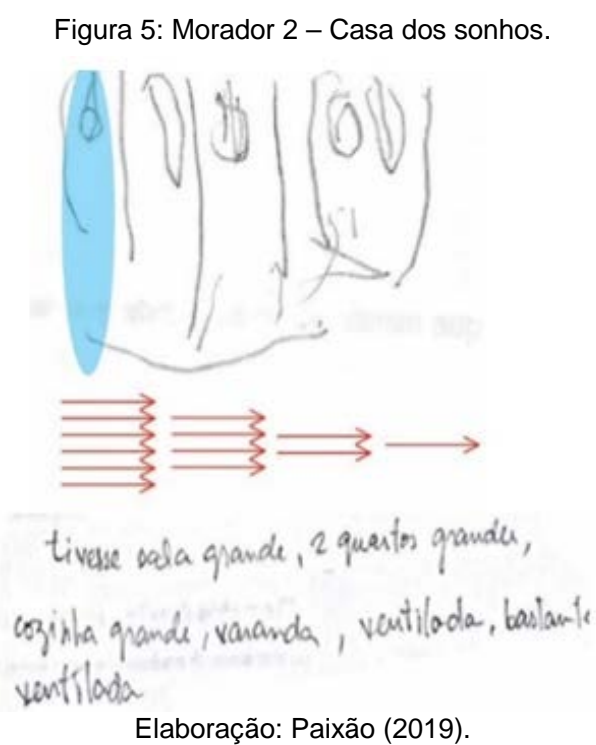

$\mathrm{Na}$ casa destino (casa entregue pelo projeto Taboquinha), foram identificados aspectos que comprometem a qualidade dos espaços e demonstram certa negligência com a dimensão humana na habitação. A categoria distância na casa do morador 2 é prejudicada pelo formato compacto da unidade que causa a exposição de todos os cômodos, tanto interna como externamente; a circulação superposta aos ambientes, bem como a configuração espacial e a disposição das aberturas comprometem o gradiente de intimidade e a privacidade de cômodos, como a cozinha e o banheiro, que, como mencionado, são ambientes, para a cultura amazônica, que ficam melhor dispostos no setor mais íntimo da casa.

As qualidades espaciais trazidas pela categoria distância também são negligenciadas no que diz respeito ao dimensionamento dos cômodos, especialmente da sala conjugada à cozinha que, além de possuir tamanho extremamente diminuto, ainda quebra um padrão espacial amazônico: o fato de esses ambientes serem separados por causa da diferença no grau de privacidade. Por fim, há a ausência de espaços de transição, como as varandas, muito comuns na Amazônia. Situações que podem ser observadas nas figuras 6a e 6b.

$6 a$

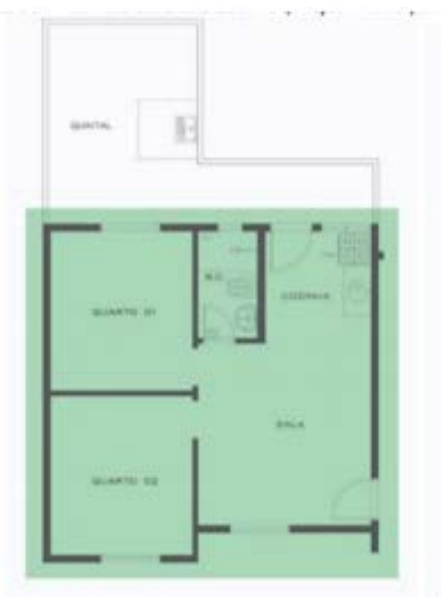

LEGENDA

FORMATO OUADRADOICOMPACTO BAIXAAMPUTUDEE ESPACIAL
Figuras 6a e 6b: Morador 2 - Casa destino sem modificações.
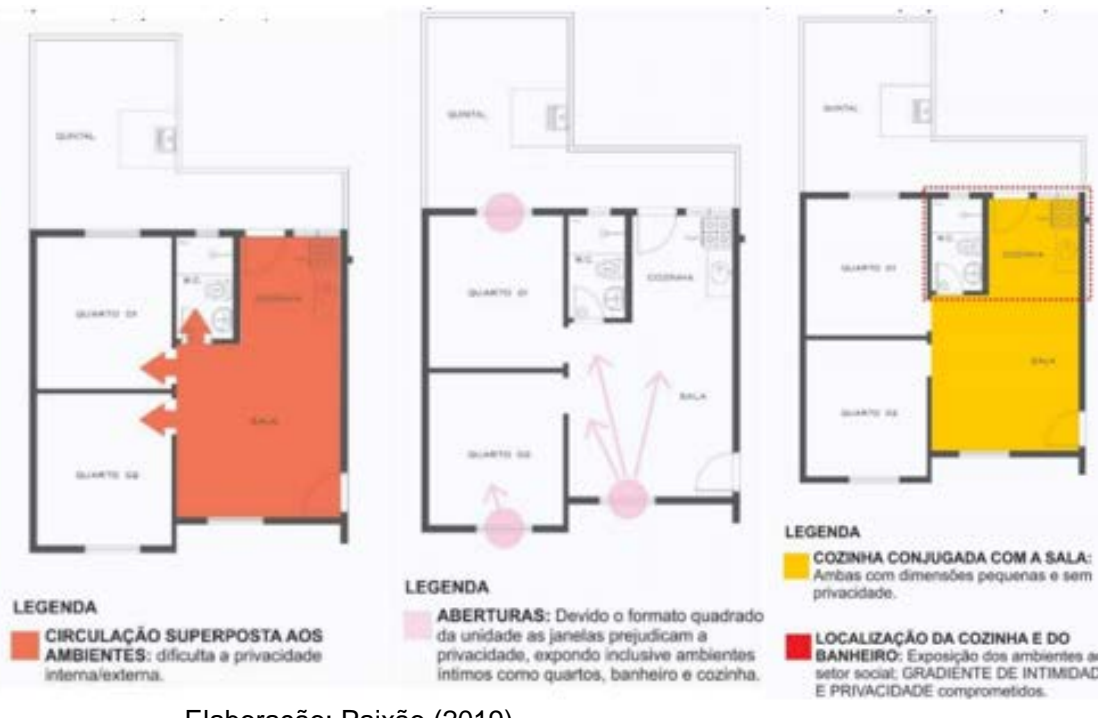

LEGENDA

COZBRA CONJUGADA COM A SALA. Ambas com dimendbes pequenas osem

LocalezacAo da CozinhaE do BANHEIRO: Exposicalo Son ambientes od Setor soodac GPUDIENTE DE INT)

Elaboração: Paixão (2019). 
$6 b$

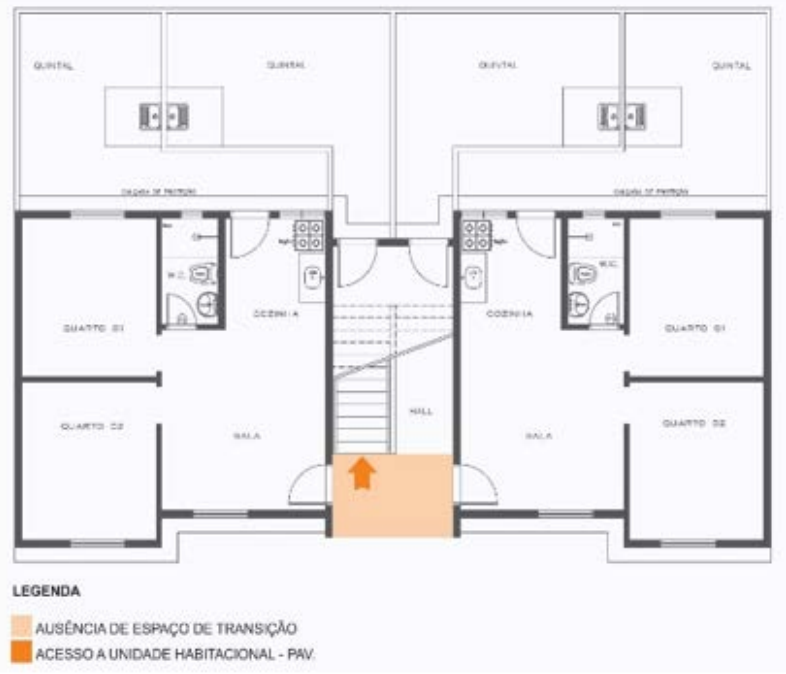

Elaboração: Paixão (2019).

Torna-se importante destacar que todos os moradores consultados já realizaram modificações na unidade recebida ou planejavam realizá-las assim que suas condições financeiras permitissem. 0 morador 2, por exemplo, já realizara modificações básicas como revestimentos internos, contudo, seus planos futuros incluíam a construção de uma cozinha na área, onde hoje fica localizado o quintal/área de serviço da casa, e a ampliação da sala.

As modificações planejadas pelo morador 2, como podem ser observadas na figura 7 , mostram as tentativas de adaptar os espaços às necessidades dos moradores e revelam, ainda, uma busca por espaços semelhantes aos da casa de origem, bem como os benefícios desses espaços - por exemplo, a nova localização da cozinha que permitirá uma privacidade maior deste ambiente, melhorando o gradiente de intimidade da casa, e a ampliação da sala que revela a necessidade por amplitude espacial. Ambas as modificações compreendem os benefícios da categoria distância.

Figura 7: Morador 2 - Casa destino com modificações.

MORADOR 02

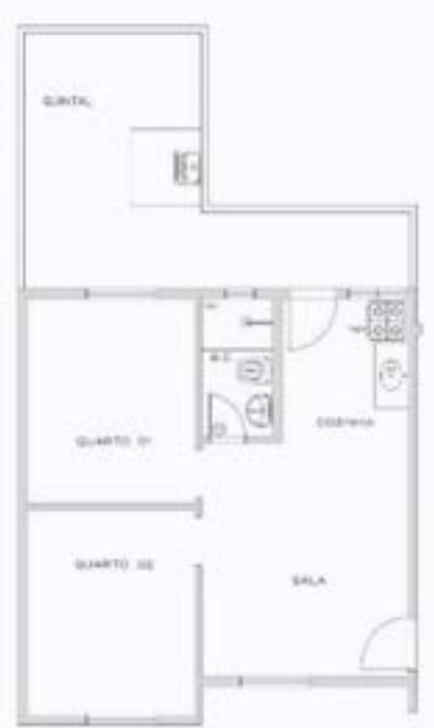

Layout Original - Tipologia Sobrado

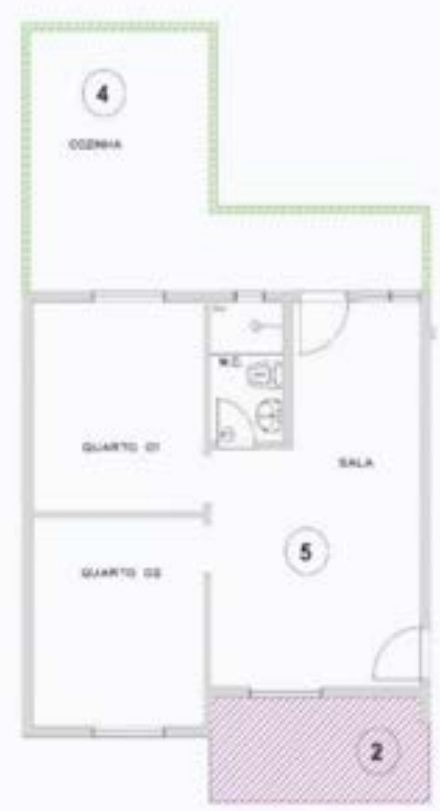

Elaboração: Paixão (2019).
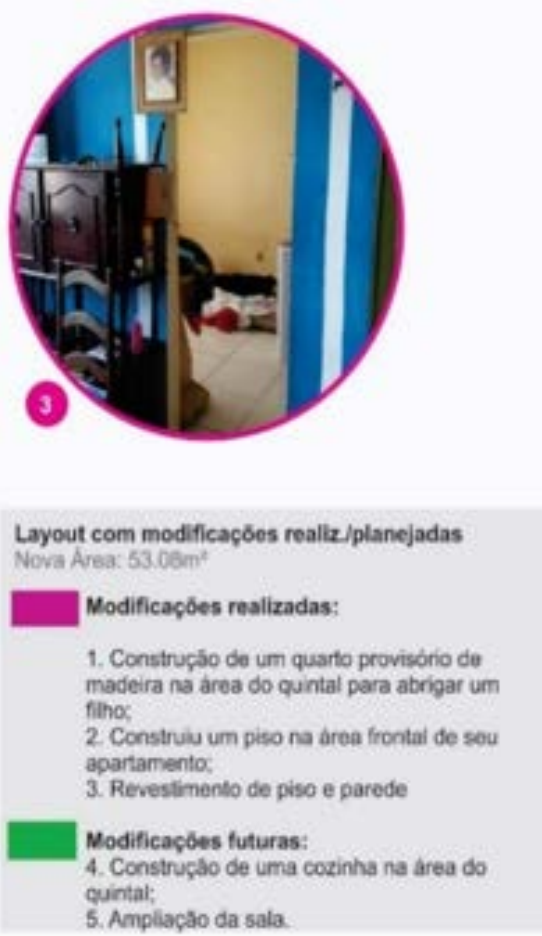
Como se pode observar, enquanto que na casa de origem foram identificadas as qualidades espaciais proporcionadas pelo uso adequado das categorias de análise aqui apresentadas, na casa destino essas qualidades encontram-se ausentes. Contudo, percebeu-se pelas modificações planejadas ou já realizadas na casa destino, que há uma busca pelos moradores para resgatar tais qualidades, mesmo que de maneira informal, já que o projeto entregue pelo órgão responsável não prevê modificações dentro da formalidade construtiva. O quadro 4 apresenta uma síntese dos resultados da espacialização das categorias analíticas na casa de origem, bem como demonstra a ausência delas na casa de destino entregue pelo projeto Taboquinha.

Portanto, as categorias de análise aqui apresentadas, ao serem associadas ao conceito de espaço pessoal e sendo correspondidas pelos parâmetros projetuais de Alexander (1977), oferecem estratégias de projeto desde o ponto de partida da concepção, as quais podem auxiliar o arquiteto na projetação de espaços que realmente atendam às necessidades dos moradores de habitação de interesse social na Amazônia.

O uso adequado da categoria distância, por exemplo, permite a compreensão das reais necessidades dos usuários e sua interação com o espaço, uma vez que considera a configuração espacial, a distribuição adequada dos ambientes de modo a permitir privacidade entre eles e o uso estratégico de aberturas tanto para ventilação quanto para amplitude espacial.

A atenção à categoria espaços de transição suave, além dos benefícios já apresentados como o de possibilitar interação social, proteção da habitação, ventilação, também oferece estratégia para a quebra da padronização, tão presente nesta produção, mas que, como discutido por Broadbent (1973), chega a ser prejudicial ao ser humano.

Ambas as categorias, quando pensadas desde a concepção projetual, permitem ao projetista elaborar projetos arquitetônicos que respeitem o lugar, uma vez que as construções irão dialogar com as tradições locais assim como com os modos de vida dos usuários.

Quadro 4: Síntese da análise por meio das categorias de análise na casa de origem e na casa destino.

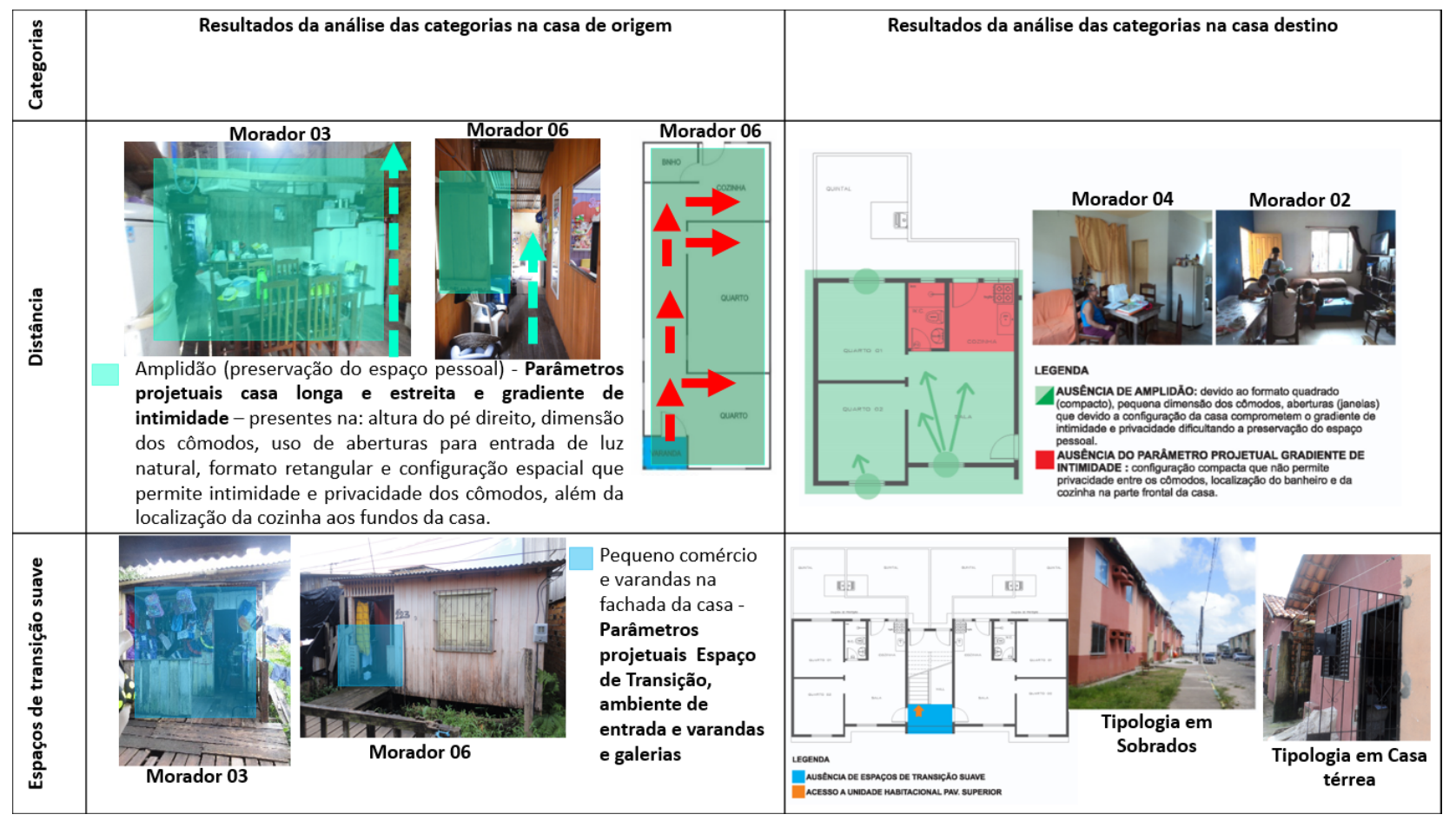

Elaboração: Autoras (2021).

Neste sentido, apontam-se como decisões projetuais que poderão nortear a produção de habitação de interesse social para a Amazônia: (I) maior dimensão dos ambientes (especialmente da cozinha); (II) uso de formas que permitam a amplitude espacial (retangular, ramificada); (III) configuração dos ambientes de modo a preservar a intimidade da família; (IV) distribuição espacial dos cômodos com atenção para a necessidade de privacidade da cozinha e do banheiro; (V) aberturas que não comprometam a privacidade 
dos ambientes da casa; (VI) presença de avarandados, pátios e pequenos comércios nas fachadas das casas.

\section{CONCLUSÃo}

Os resultados alcançados pela associação das categorias analíticas de Gehl (2013) aos parâmetros projetuais de Alexander (1977), somadas, ainda, ao conceito de espaço pessoal (SOMMER, 1969) podem oferecer resposta eficaz para o atendimento das necessidades humanas em habitação social para a Amazônia. Quando analisadas na escala do edifício, as categorias investigadas se mostraram relevantes no sentido de resgatar o ser humano com suas necessidades, expectativas, desejos, percepções e interação com o espaço construído, especialmente por se tratar de um programa de habitação social.

As categorias foram evidenciadas a partir dos estudos nas casas de origem dos moradores e nas casas dos sonhos e estão sendo resgatadas nas casas destino (entregues pelo projeto Taboquinha), por meio das modificações realizadas e planejadas pelos moradores, o que permite apontá-las como categorias relevantes para auxiliar o projetista como ponto de partida na concepção da habitação social na Amazônia.

Como analisado, as categorias encontram materialidade no ambiente por meio de procedimentos triviais do percurso projetual, contudo, eles poderão ser melhor qualificados quando a profundidade do habitar ganha atenção pelo projetista no que se refere ao dimensionamento dos cômodos (especialmente da cozinha), à configuração espacial e formato da unidade que permita privacidade entre os ambientes; à distribuição de cômodos que possibilite a preservação da intimidade nas relações familiares, como também uma melhor possibilidade de conformação do espaço pessoal; além das aberturas que preservam a intimidade dos usuários associadas a avarandados, que, dentre tantas funções, servem para a apreciação e a socialização, contribuindo para a privacidade, segurança da casa e quebra da monotonia externa trazida pela extrema padronização neste tipo de produção.

A pesquisa também demonstrou que a ampliação do olhar sobre a dimensão humana ultrapassa os aspectos ligados ao espaço físico-geométrico e adentra as relações espaciais que o usuário mantém com o espaço em uso - situação que ficou evidente pela seleção das categorias analíticas que possuem uma natureza topológica, já que relações espaciais que não são descritas pela geometria encontram respaldo geométrico quando se materializam espacialmente.

Entende-se que o objetivo do presente trabalho foi alcançado, na medida em que o artigo apresentou a sistematização das categorias analíticas, as quais, auxiliadas pelos parâmetros projetuais de Alexander (1977), apontam para decisões projetuais que contribuem para o resgate da dimensão humana no projeto arquitetônico, podendo, dessa forma, auxiliar arquitetos/projetistas na concepção de habitação social de qualidade, neste setor, para a Amazônia. Destaca-se também que, uma vez evidenciadas nas casas de origem dos moradores (palafita), as categorias podem somar para a contínua caracterização da palafita amazônica, contribuindo com as investigações de Menezes (2015), Menezes, Perdigão e Pratschke (2015) e Perdigão (2016), uma vez que, como mencionado, as palafitas amazônicas têm demonstrado serem as principais referências para a produção habitacional em áreas de assentamentos precários nas áreas alagadas e alagáveis da cidade de Belém (PA).

\section{REFERÊNCIAS}

ABELÉM, A.G. Urbanização e remoção: por que e para quem? Belém: NAEA/UFPA, 1989.

AGUIAR, D.V. Planta e corpo: elementos de topologia na arquitetura. In: DUARTE, C. R.; RHEINGANTZ, P. A.; AZEVEDO, G.; BRONSTEIN, L. (Orgs.). O lugar do projeto: no ensino e na pesquisa em arquitetura e urbanismo. Rio de Janeiro: Contra Capa Livraria, 2005. pp. 388-396.

ALEXANDER, C. A pattern language: towns, buildings, construction. Oxford: University Press, 1977.

AULT, R.L. Desenvolvimento cognitivo da criança: a teoria de Piaget e a abordagem de processo. Rio de Janeiro: Zahar, 1978.

BARROS, R. M. P.; PINA, S. M.; KOWALTOWSKI, D. C. C. K.; FUNARI, T. B.; ALVES, S.; TEIXEIRA, C.; COSTA, A. Conforto e Psicologia ambiental: a questão do espaço pessoal no projeto arquitetônico. In: ENCAC-ELACAC. Anais... Maceió, 2005.

BARROS, R.R.M.P. Habitação coletiva: a inclusão de conceitos humanizadores no processo de projeto. 2008. Tese (Doutorado em Engenharia Civil) - Faculdade de Engenharia Civil, Arquitetura e Urbanismo, Universidade Estadual de Campinas, Campinas, 2008. 
BARROS, R. R. M. P.; PINA, SAMG, A. Humanização no projeto da habitação coletiva. In: KOWALTOWSKI, D.K.; MOREIRA, D.C.; PETRECHE, J.R.D.; FABRÍCIO, M.M. O processo de projeto em arquitetura: da teoria a tecnologia. Campinas: Oficina de Textos, 2011. pp. 245-272.

BARKI, J. O aprendizado do fazer. In: OLIVEIRA, B. S.; PEIXOTO, G. R.; LASSANCE, G.; BRONSTEIN, L. (Org.). Leituras em Teoria da Arquitetura. Rio de Janeiro: Viana \& Mosley, 2009.

BRASIL. Associação Brasileira de Cohabs e Agentes Públicos de Habitação. Fórum Nacional de Secretários de Habitação e Desenvolvimento Urbano. 2012. Disponível em: http://abconline.org.br/biblioteca/selo-de-merito/. Acesso em 19 de fevereiro de 2021.

BROADBENT, G. Design in architecture: architecture and the human sciences. London: Wiley, 1973.

COMPANHIA DE HABITAÇÃO DO PARÁ. Plano de Remanejamento Comunidade Taboquinha. Belém, 2009.

COMPANHIA DE HABITAÇÃO DO PARÁ. Plano de Remanejamento Comunidade Taboquinha. Belém, 2011.

ELALI, G. A.; PINHEIRO, J. Q. Edificando espaços, enxergando comportamentos: por um projeto arquitetônico centrado na relação pessoa-ambiente. In: MARQUES, S.; LARA, F. L. C. (Orgs.). Projetar: desafios e conquistas da pesquisa e do ensino de projeto. Rio de Janeiro: Editora Virtual Científica, 2003. pp. 130-144.

ELALI, G. A.; PINHEIRO, J. Q. Qualidade ambiental na habitação: avaliação pós-ocupação. São Paulo: Oficina de Textos, 2013. p. 15-35.

FERNÁNDEZ-LLEBREZ MUÑOZ, J. La dimensión humana de la arquitectura. Aprendiendo del Team 10. Arquitectura y Urbanismo. n. 1, v. 34. pp. 64-72, 2013.

GEHL, J. Cidade para Pessoas. São Paulo: Perspectiva, 2013.

GIFFORD, R. Environmental psychology. Boston: Allyn \& Bacon, 1997.

GLIBER, A. R.; CHIPPARI, M. Invasão do espaço pessoal: um estudo observacional em uma biblioteca universitária. Psicólogo informação. n. 11,v. 11. pp. 9-26, 2007.

HALL, E. A dimensão oculta. Rio de Janeiro: Francisco Alves, 1981.

IACHINI, T. Personal Space. In: ELSEVIER. Reference Module in Neuroscience and Biobehavioral Psychology. Cambridge, 2017

KUPRITZ, V. W. Privacy management at work: A conceptual model. Journal of Architectural and Planning Research. pp. 47-63, 2000.

MALARD, M. L. As aparências em arquitetura. Belo Horizonte: Editora UFMG, 2006.

MENEZES, T. M. S. Referências ao projeto de arquitetura pelo tipo palafita amazônico na Vila da Barca (Belém-PA). Belém, 2015. Dissertação (Mestrado em Arquitetura e Urbanismo) - Programa de Pós-Graduação em Arquitetura e Urbanismo, Universidade Federal do Pará, Belém, 2015.

MENEZES, T. M.; PERDIGÃO, A. K. de A. V.; PRATSCHKE, A. O tipo palafita amazônico: contribuições ao processo de projeto de arquitetura. Oculum Ensaios, v. 12, n. 2, p. 237-254, 2015.

MENEZES, T. M. dos S.; PERDIGÃO, A. KI. de A. V. O tipo palafita amazônico: entre formalidade e informalidade do habitar na Vila da Barca (Belém, Pará, Brasil). Revista PROJETAR, 6(2), 2021, p. 44-59.

PAIXÃO, R.T da. Estudo longitudinal de famílias remanejadas e reassentadas no Projeto Taboquinha (Icoaraci, Belém, Pará) como subsídio ao projeto de arquitetura em habitação social. Dissertação (Mestrado em Arquitetura e Urbanismo) - Universidade Federal do Pará. Belém, 2019.

PERDIGÃO, A. K. de A. V. A dimensão afetiva da arquitetura de espaços habitacionais. São Paulo, SP: USP, 2005. Originalmente apresentada como tese de doutorado, Universidade de São Paulo, 2006.

PERDIGÃO, A. K. A. V. \& BRUNA, G. C. Representações espaciais na concepção arquitetônica. Anais IV PROJETAR: Projeto com a investigação: ensino, pesquisa e prática. São Paulo: Alter Market, 2009.

PERDIGAO, A. K. A. V. Investigações sobre a interação entre ser humano e ambiente construído pelo projeto de arquitetura. In: II ENCONTRO DA ASSOCIAÇÃO NACIONAL DE PESQUISA E PÓS-GRADUAÇÃO EM ARQUITETURA E URBANISMO - Teorias e práticas na Arquitetura e na Cidade Contemporâneas, 2012, Natal. Anais... UFRN, 2012.

PERDIGÃO, A. K. A. V. Tipo e tipologia na palafita amazônica da cidade de Afuá. V!RUS, São Carlos, n. $13,2016$. Disponível em: <http://www.nomads.usp.br/virus/virus13/?sec=4\&item=2\&lang=pt>. Acesso em: 08 m. 2021.

RAPOPORT, A. Home environments. Boston: Springer, 1985. pp. 255-286. 
REIS, A.T.L.; LAY, M.C.D. Privacidade na habitação: atitudes, conexões visuais e funcionais. Ambiente construído. $n$. 4 , v. 3. pp. 21-33, 2003.

SOMMER, R. Personal space: the behavioral bases of design. New York: Prendice Hall, 1969.

NOTA DO EDITOR (*): O conteúdo do artigo e as imagens nele publicadas são de responsabilidade do(s) autor(es). 